\title{
BACTERIAL AND FUNGAL CONTAMINATION OF DENTAL HYGIENISTS' HANDS WITH AND WITHOUT FINGER RINGS
}

\author{
Giuseppe A. M essano
}

\begin{abstract}
SAPIENZA UNIVERSITY, DEPARTMENT OF PUBLIC HEALTH AND INFECTIOUS DISEASES, ROME, ITALY;
\end{abstract}
\begin{abstract}
Introduction. The role of healthcare workers' hands in the transmission of infectious diseases to patients is acknowledged. Indeed, they can pick potentially pathogenic bacteria and fungi from hand-touch surfaces before wearing gloves; these microorganisms multiply rapidly in the moist environment underneath gloves and multiplication rate increases along with the duration of glove use. This route of infection transmission through healthcare workers' hands is the foundation of the recommendation for hand hygiene, which is compulsory despite the use of disposable gloves. The use of finger rings is responsible for glove donning with consequent hand contamination, and imperfect hand hygiene.
\end{abstract}

Aim. To investigate the occurrence of potentially pathogenic bacteria and fungi on hands underneath the gloves of dental hygienists (DHs) with and without finger rings.

$M$ aterial and methods. Forty DHs (17 with rings -RDH, 23 without rings $-N R D H)$, were considered. Skin samples from the dominant hand soon after professional toothcleaning and glove removal were collected. Prevalence of potentially pathogenic bacteria and fungi were investigated with cultural and biochemical laboratory methods.

Results. Bacteria and fungi were significantly more frequent in RDHs than in NRDHs: $65 \%$ vs. $30 \%$ (bacteria), $82 \%$ vs. $17 \%$ (fungi). Potentially pathogenic microorganisms isolated were Staphylococcus aureus, Staphylococcus epidermidis, Escherichia coli, Enterococcus, Candida albicans, Aspergillus niger, Aspergillus flavus. All these microorganisms, excluding $S$. aureus, were more frequent in RDHs.

Conclusion. In the present sample potentially pathogenic microorganisms were more frequent in $\mathrm{DH}$ who wore rings.

Key words: dentistry, dental hygienist, hand hygiene, gloves, infection transmission, Staphylococcus aureus, Staphylococcus epidermidis, candida

\section{Introduction}

Contamination of noncritical environmental surfaces is responsible for healthcare associated infections and for the transmission of pathogens such as methicillin-resistant Staphylococcus aureus (MRSA), vancomycin-resistant Enterococcus, Klebsiella pneumoniae, etc. ${ }^{1,2}$. Studies on M RSA suggest that the role of environment and healthcare workers is frequently responsible for microorganism acquisition and infection. In general, healthcare workers are not carriers but vectors. Indeed, MRSA are spread in the environment by patients who are carriers, particularly in special settings, are picked up by healthcare workers through hands, gloved or not, and are transmitted to other patients with open wounds or lesions or during invasive treatments 3,4 . Clinical contact surfaces are a subset of noncritical environmental surfaces typical of dental health care settings and are defined by the Centres for Disease Control and Prevention (CDC) "surfaces that can be directly contaminated from patient materials either by direct spray or splatter generated during dental procedures or by contact with dental health care provider's gloved hands...". Examples of such surfaces include light and door handles, switches, dental X-ray equipment, dental chair, pens, telephone, doorknobs, etc. Contamination of these surfaces is frequently reported but the

(C) 2013 Faculty of Medicine in Niš. Clinic of Dentistry in Niš. All rights reserved / (C) 2013 Medicinski fakultet Niš. Klinika za stomatologiju Niš. Sva prava zadržana
Address for correspondence:

Dr. Giuseppe Alessio Messano

Department of Public Health and Infectious Diseases

Sapienza University

P.le Aldo Moro 5, 00185 Rome, Italy

Phone/Fax: +3906 49914667

Email: giuseppe.messano@yahoo.it 
risk of infection for patients and dental staff is not yet determined with high accuracy ${ }^{5-8}$.

Dental healthcare workers' skin could transiently carry potential pathogens coming from the environment and the use of gloves does not automatically eliminate the need for hand washing, because gloves can have unapparent defects or can be torn during use, due to sharp equipment, widespread in dental healthcare. In addition, opportunistic pathogens may multiply rapidly in the moist environment underneath gloves and multiplication rate increases along with the duration of glove use ${ }^{5}$. The risk of infection transmission to patients through gloved hands is not demonstrated in dental healthcare settings but it is frequently reported for surgical site infections and in intensive care units, the first situation could occur in dental healthcare settings ${ }^{10}$.

An aspect associated with microbial contamination of gloved hands is the use of finger rings. Indeed, rings and decorative nail jewellery can make glove donning difficult with consequent damage and loss of integrity. In addition, several studies have demonstrated that skin underneath rings is more heavily colonized than comparable areas of skin on fingers without rings. However, whether wearing rings increases the likelihood of transmitting pathogens is unknown ${ }^{11}$.

\section{Aim}

The aim of the present study was to investigate the occurrence of potential pathogenic bacteria and fungi on skin of gloved hands of dental healthcare workers who wore and did not wear finger rings.

\section{M aterial and M ethods}

The study was made on forty Dental Hygienists $(\mathrm{DH})$ working in private offices of Rome, Italy, who provided their informed consent to study participation. General Dental Practitioners (GDPs) were contacted before registering to Continuing $\mathrm{M}$ edical $\mathrm{Education}$ courses, as explained elsewhere ${ }^{12}$, GDPs who had DHs working in their offices were asked to contact them and to invite them to participate to the study. Participation was on a voluntary basis and there were no incentives. Data protection and anonymity were guaranteed. The study protocol was approved by the Review Board of the Medical and Dental Association of Rome.

Skin samples were collected in the middle of the working day from the dominant hand soon after professional toothcleaning and glove removal. Sterile swabs were previously moistened into tubes containing $1 \mathrm{ml}$ of sterile saline solution $(0.9 \% \mathrm{w} / \mathrm{v} \mathrm{NaCl})$. Swabs were rubbed over the entire ventral surface of the hand and over both sides of rings, when they were present. Swabs were immediately passed on plates containing Columbia Agar supplemented with 5\% sheep blood (non-selective medium), Mannitol Salt Agar (selective for staphylococci), Eosin Methylene Blue Agar (selective for Gram negative bacteria) and Sabouraud Dextrose Agar (selective for fungi) (Becton Dickinson Italia, Buccinasco, Italy). Plates were incubated aerobically at $28^{\circ} \mathrm{C}$ and $37^{\circ} \mathrm{C}$ for 48 h. Isolates recovered from cultures were preliminarily subjected to conventional microbiological procedures (colony morphology, Gram staining, catalase, oxidase, coagulase reactions) and were presumptively identified using VITEK-2 (BioMérieux, Italia; Bagno a Ripoli, Italy). Further biochemical identification tests were not made. The laboratory procedures were not made by the authors of this study but were made by courtesy of Prof. Mario Mancini from the Microbiology Section of the Department of Public Health and Infectious Diseases of the Sapienza University of Rome.

Prevalence of potential pathogenic microorganisms with and without rings was assessed and differences were statistically analysed with $\chi^{2}$ test with Yates correction for continuity. Prevalence ratio (PR), with 95\% confidence interval $(95 \mathrm{CI})$, an estimate of the risk of detecting bacteria and fungi in ring wearers, al so was assessed using ring non-wearers as reference group and wearers as risk group. A level of significance of $95 \%$ was chosen.

\section{Results}

All DHs were females aged between ${ }^{23}$ and 41 years (mean, 32.5 years), $42.5 \%$ of them $(\mathrm{N}=17)$ with finger rings and $57.5 \%(\mathrm{~N}=23)$ without finger rings (Table 1). Mean ages of DHs wearing and not wearing rings were 30.6 
and 33.9 years (Student's unpaired t-test, 2.00; $p=0.05$, data not in Table). The mean toothcleaning duration ranged between 15 and $60 \mathrm{~min}$ (data not in Table). Overall potential pathogens were detected in $88.2 \%$ and $43.5 \%$ of subjects with and without rings, respectively $(\mathrm{p}=0.01-$ Table 1). Bacteria were non-significantly more frequent in ring wearing DHs (65\% vs. $30 \%$; $\mathrm{p}=0.06$ ). Excluding Staphylococcus epidermidis, a common skin colonizer ${ }^{13}$, prevalence of potentially pathogenic bacteria was $23.5 \%$ and $9 \%$ in ring wearing and non-wearing DHs. Fungi also were significantly more frequent among ring wearers $(82 \%$ vs. $17 \%$; $p=0.0002)$. All estimated PRs were high, ranging between 2.03 and 4.74 , but were statistically not significant at 95\% level excluding PR for fungi (Table 1).

\section{Discussion}

The present study is one of the papers presented at the workshop "Advances in Infection Epidemiology and Control in Dental Healthcare Settings", Department of Public Health and Infectious Diseases, Sapienza University, Rome, Italy on February 9th, 2013 ${ }^{14-20}$.

One important limit of this study was the small size of the sample, which led to high levels of alpha and beta errors. In other terms, some of the reported non-significant differences between DHs who wore and did not wear rings could be statistically significant and, vice versa, some of the observed significant differences could be due to chance. Therefore, it was not possible to make robust inference regard-

Table 1. Occurrence of potential pathogens in skin samples from hands with and without finger rings of dental hygienists. Statistical analysis of differences ( $\chi 2$ test with Yates correction for continuity).

\begin{tabular}{|c|c|c|c|c|}
\hline $\begin{array}{l}\text { Ring } \\
\text { wearing }\end{array}$ & $\begin{array}{l}\text { Overall } \\
\text { pathogens }\end{array}$ & Bacteria & $\begin{array}{l}\text { Bacteria (excluding } S \text {. } \\
\text { epidermidis) }\end{array}$ & Fungi \\
\hline No $(\mathrm{N}=23)$ & $43.5 \%(10 / 23)$ & $30.4 \%(7 / 23)$ & $8.7 \%(2 / 23)$ & $17.4 \%(4 / 23)$ \\
\hline Yes $(\mathrm{N}=17)$ & $88.2 \%(15 / 17)$ & $64.7 \%(11 / 17)$ & $23.5 \%(4 / 17)$ & $82.4 \%(14 / 17)$ \\
\hline PR (95CI) & $2.03(0.37-11.00)$ & $2.13(0.56-8.08)$ & $2.70(0.43-16.88)$ & $4.74(0.91-26.64)$ \\
\hline$\chi 2$ test & $6.55(\mathrm{p}=0.01)$ & $3.36(p=0.06)$ & $0.72(p=0.39)$ & $14.15(\mathrm{p}=0.0002)$ \\
\hline
\end{tabular}

Potentially pathogenic bacteria which were isolated were S. aureus, S. epidermidis, Escherichia coli, Enterococcus spp., while fungi were Candida albicans, Aspergillus niger and Aspergillus flavus. Excluding S. aureus which was isolated only in one ring non-wearing $\mathrm{DH}$, all these microorganisms were more frequent in ring wearing DHs (Table 2). In six cases (2 ring non-wearers, ${ }^{4}$ wearers) DHs harboured two different bacteria, one of the two was always $S$. epidermidis (data not in Table). ing the category of DHs and dental healthcare workers. Nevertheless, in the present sample, DHs who wore rings were two times more likely to harbour potential pathogenic bacteria (PR, 2.13 -Table 1) and almost five times more likely to harbour fungi (PR, 4.74 -Table 1) than DHs who did not wear rings.

The results of the present study are similar to studies made in different healthcare settings. In a sample of 84 nurses working in intensive care units, those who wore rings showed more Gram

Table 2. List of potential pathogenic bacteria and fungi isolated from skin samples of dental hygienists' hands with and without finger rings (prevalence values between brackets).

\begin{tabular}{llll}
\hline & All dental hygienists & Ring non-wearers & Ring wearers \\
\hline & Potentially pathogenic bacteria & & \\
Staphylococcus aureus & $1(2.5 \%)$ & $1(4.3 \%)$ & 0 \\
Staphylococcus epidermidis & $14(35.0 \%)$ & $7(30.4 \%)$ & $7(41.2 \%)$ \\
Escherichia coli & $3(7.5 \%)$ & 0 & $3(17.6 \%)$ \\
Enterococcus spp. & $3(7.5 \%)$ & $1(4.3 \%)$ & $2(11.8 \%)$ \\
Candida albicans & Potentially pathogenic fungi & $4(17.4 \%)$ & $12(70.6 \%)$ \\
Aspergillus niger & $16(40.0 \%)$ & 0 & $3(17.6 \%)$ \\
Aspergillus flavus & $3(7.5 \%)$ & 0 & $1(5.9 \%)$ \\
\hline
\end{tabular}


positive and Gram negative bacteria than those who did not wear rings, while no difference was found between nurses wearing plane wedding rings and those wearing rings with stones. Very importantly, samples were collected after hand cleaning with alcohol and rubbing ${ }^{21}$. A nother group of 66 intensive care unit nurses was tested for the effects of rings. Authors reported that the odds ratios for the detection of fungi, S. aureus and Gram negative bacteria were 2.8 (95CI, 1.3-6.2), 2.1 (95CI, 1.0-0.4) and 2.9 (95CI, 1.55.8), while the use of alcohol rubbing was significantly more effective than water and soap ${ }^{22}$. A simulation with manikins showed that rings were not associated with higher level of hand contamination but with more difficult cleaning. However, when washing with soap and rubbing was prolonged up to $25 \mathrm{~s}$, cleaning level around fingers with and without rings was similar ${ }^{23}$. In a sample of twenty veterinary medical students, ten wearing plain rings, ten not wearing rings, no difference in viable flora was detected between ring and non-ring hands ${ }^{24}$. In a sample of 200 healthcare workers from an intensive care unit, ring wearers showed almost double prevalence of Gram negative bacteria and Enterobacteriaceae than non-wearers, but no difference with respect of S. aureus ${ }^{25}$. Finally, in a sample of laboratory staff, subjects with rings, bracelets and watches showed potential pathogens after hand hygiene ${ }^{26}$. In an attempt to summarize these data, we could speculate that ring wearing is associable with higher level of bacteria and fungi, including potential pathogens. Such a high contamination level could be due to the lower effectiveness of hand hygiene in ring wearers than in non-wearers. In addition, the residual and relatively high level of contamination, due to inefficient hygiene, will increase during the working day, because of bacterial and fungal multiplication on the warm and moistened environment of skin beneath gloves.

If bacterial and fungal colonization by healthcare workers who wear rings is more likely than in those who do not wear rings, another important question is to assess the risk for infection, as certain types of contaminations, like, for example, the output water of dental unit waterlines does not necessarily result in infectious disease development ${ }^{27}$. In a simulation of bacterial transmission, healthcare workers who wore and did not wear rings during routine practice, exchanged hand-shakes with an investigator. Transmission from healthcare workers to the investigator of Gram negative bacteria, Enterobacteriaceae, S. aureus was similar in the two groups, thus suggesting that the high level of hand contamination in ring wearing subjects, did not result in higher rate of pathogen transmission ${ }^{28}$. A Cochrane systematic review seeking to investigate whether finger ring removal by healthcare providers may help prevent surgical infection reported insufficient evidence in support of this hypothesis ${ }^{11}$.

M ost of studies aimed at investigating the problem of ring wearing were made in intensive care units, where immune-compromised patients are hospitalised and multiple drug resistant microorganisms are frequently detected. Therefore, it is not possible to extend most of the reported data to dental healthcare settings, where the majority of patients are not immune deficient and medical/surgical procedures are not as invasive as in intensive care units. Our data cannot help provide any evidence in support or against an increased risk of infection transmission due to ring wearing in dental healthcare workers. However, most of the microorganisms detected in significantly higher frequency in ring wearers were not potential pathogens for healthy patients, since S. epidermidis is a usual skin resident ${ }^{13}$ and fungi (Table 2 ). Although fungal detection in the oral cavity of patients is predictive of Candida infection, such an association is only suggestive of poor general conditions, such as elderly, presence of endocrine diseases, poor nutritional status, prolonged hospitalization, etc. ${ }^{29}$.

\section{Conclusion}

In conclusion, the data from this study, the first ever made in dental healthcare settings, suggest that in the present sample, potential pathogens are more likely to be detected in the hands of dental hygienists who wore rings. However, the nature of these microorganisms does not support the idea that ring wearing could increase the risk of infection in dental patients. 


\section{LITERATURA / REFERENCES}

1. Khan AS, Dancer SJ, Humphreys H. Priorities in the prevention and control of multidrug-resistant Enterobacteriaceae in hospitals. J Hosp Infect 2012;82(2):8593.

2. Smith SJ, Young V, Robertson C, Dancer SJ. Where do hands go? An audit of sequential hand-touch events on a hospital ward. J Hosp Infect 2012;80(3):206-11.

3. Albrich WC, Harbarth S. Health-care workers: source, vector, or victim of MRSA? Lancet Infect Dis 2008;8(5):289-301.

4. Dancer SJ. Importance of the environment in methicillin-resistant Staphylococcus aureus acquisition: the case for hospital cleaning. Lancet Infect Dis 2008;8:101-13.

5. Kohn W G, Collins A S, Cleveland J L et al. Guidelines for infection control in dental health-care settings, 2003. MMWR Recomm Rep 2003;52(RR-17):1-61.

6. Petti S, Polimeni A. Risk of methicillin-resistant Staphylococcus aureus transmission in the dental healthcare setting: a narrative review. Infect Control Hosp Epidemiol 2011;32(11):1109-15.

7. Roberts M C, Soge 00, Horst JA, Ly K A, M ilgrom P. Methicillin-resistant Staphylococcus aureus from dental school clinic surfaces and students. Am J Infect Control 2011;39(8):628-32.

8. Petti S, Polimeni A. Methicillin-resistant Staphylococcus aureus infection transmission in dental health care settings: myths and facts. Am J Infect Control 2012;40(3):287-8.

9. National Nosocomial Infections Surveillance System. National Nosocomial Infections Surveillance (NNIS) System Report, data summary from January 1992 through June 2004, issued October 2004. Am J Infect Control 2004;32(8):470-85.

10. Rosenthal VD, Bijie H, Maki DG et al. International Nosocomial Infection Control Consortium (INICC) report, data summary of 36 countries, for 2004-2009. Am J Infect Control 2012;40(5):396-407.

11. Arrowsmith VA, Taylor R. Removal of nail polish and finger rings to prevent surgical infection. Cochrane Database Syst Rev 2012 16;5:CD003325.

12. Messano GA, Petti S. General dental practitioners and hearing impairment. J Dent 2012;40(10):821-8.

13. Otto M. Staphylococcus colonization of the skin and antimicrobial peptides. Expert Rev Dermatol 2010;5(2):183-95.

14. Messano GA, Sofan AAA, Petti S. Quality of air and water in dental healthcare settings during professional toothcleaning. A cta Stomatol Naissi 2013; 29(67): 1230-35; doi: 10.5937/asn1367230M.

15. Messano GA, Masood M, Palermo P, Petti S. Predictors of Legionella occurrence in dental unit waterlines of a highly colonized dental hospital. Acta Stomatol Naissi 2013; 29(67): 1236-41; doi: 10.5937/asn1367236M.
16. Messano GA, Masood M, Palermo P, Petti S. Prevalence of reactive tuberculin skin test in dental healthcare workers and students. Acta Stomatol Naissi 2013; 29(67): 1242-48; doi: 10.5937/asn1367242M.

17. Petti S, Sofan AAA, Messano GA. Streptococcus pneumoniae carriage rate in healthy preadolescent dental patients. Acta Stomatol Naissi 2013; 29(67): 1249-54; doi: 10.5937/asn1367249P.

18. Messano GA, De Bono V, Architrave R, Petti S. Environmental and gloves' contamination by staphylococci in dental healthcare settings. A cta Stomatol $\mathrm{N}$ aissi 2013; 29(67): 1255-59; doi: 10.5937/asn1367255M.

19. Petti S, Messano GA, Polimeni A, Dancer SJ. Effect of cleaning and disinfection on naturally contaminated clinical contact surfaces. A cta Stomatol Naissi 2013; 29(67): 1265-72; doi: 10.5937/asn1367265P.

20. Petti S, Messano GA, Scully C. Antibody level and immunity against Hepatitis B virus infection among general dental practitioners. Acta Stomatol Naissi 2013; 29(67): 1273-78; doi: 10.5937/asn1367273P.

21. Yildirim I, Ceyhan M, Cengiz AB et al. A prospective comparative study of the relationship between different types of ring and microbial hand colonization among pediatric intensive care unit nurses. Int J Nurs Stud 2008;45(11):1572-6.

22. Trick WE, Vernon MO, Hayes RA et al. Impact of ring wearing on hand contamination and comparison of hand hygiene agents in a hospital. Clin Infect Dis 2003;36(11):1383-90.

23. Alur AA, Rane MJ, Scheetz JP, Lorenz DJ, Gettleman L. Simulated microbe removal around finger rings using different hand sanitation methods. Int J Oral Sci 2009;1(3):136-42.

24. Waterman TR, Smeak DD, Kowalski J, Hade EM. Comparison of bacterial counts in glove juice of surgeons wearing smooth band rings versus those without rings Am J Infect Control 2006;34(7):421-5.

25. Fagernes $M$, Lingaas E. Impact of finger rings on transmission of bacteria during hand contact. Infect Control Hosp Epidemiol 2009;30(5):427-2.

26. Alp E, Haverkate D, Voss A. Hand hygiene among laboratory workers. Infect Control Hosp Epidemiol 2006;27(9):978-80.

27. Petti S, Moroni C, Messano GA, Polimeni A. Detection of oral streptococci in dental unit water lines after therapy with air turbine handpiece: biological fluid retraction more frequent than expected. Future Microbiol 2013;8(3):413-21.

28. Fagernes M, Lingaas E. Impact of finger rings on transmission of bacteria during hand contact. Infect Control Hosp Epidemiol 2009;30(5):427-32.

29. Fanello S, Bouchara JP, Sauteron M et al. Predictive value of oral colonization by Candida yeasts for the onset of a nosocomial infection in elderly hospitalized patients. J Med Microbiol 2006;55(Pt 2):223-8. 